\title{
Caring for patients harmed by treatment
}

\author{
Charles Vincent
}

I felt as though the medical authorities were clamming up as soon as I expressed my concern over the way I looked. . . . So much evidence has come to light (after seeing a solicitor).... If nothing else comes from all this, I have the satisfaction of knowing that it wasn't just my imagination or me simply making a fuss.

The lawyer has just sent me a negative report which may terminate any possible case but this kind of careful and detailed report could have avoided many years of anguish if supplied soon after my reaction to the news of my daughter's damage. ${ }^{1}$

Patients and relatives may suffer in two ways from injuries due to treatment. Firstly, from the injury itself and, secondly, from the way the incident is handled afterwards. Many people harmed by their treatment suffer further trauma through the incident being handled insensitively and inadequately. Conversely, when staff come forward, acknowledge the damage, and take the necessary action the overall trauma can be greatly reduced.

Many people dealing with injured patients are not directly involved in clinical work. It is not easy to appreciate in, say, the quiet of a barrister's chambers just what a lifetime of chronic pain means. Those acting for hospitals may never even meet the patients involved, except in court. Staff involved in the original incident may not be those involved in rehabilitation and later treatment. The experience of injured patients therefore tends not to be fully appreciated, especially when they become labelled as litigants.

Although there is some evidence that some injured patients are harmed further by subsequent clinical mismanagement, ${ }^{2}$ I will assume here that medical treatment is adequate once the patient's problem has been recognised. The same cannot be said for the attention given to patients' psychological and social problems, which are complex, fluctuating, and not well understood.

\section{Psychological reactions to injury}

The speed and extent of recovery from any injury depend on many different factors. The nature and extent of the injury, the degree of pain, and the degree of subsequent disability are crucial; the personality of the affected patients, the history of previous trauma and loss in their lives, and their financial security and employment prospects may also influence subsequent adjustment. Although reactions to injury vary greatly, certain constellations of symptoms recur.

Traumatic and life threatening events produce various symptoms over and above any physical injury. Anxiety, intrusive memories, emotional numbing, and flashbacks are all common sequelae and important components of post-traumatic stress disorder. ${ }^{3}{ }^{4}$ Sudden, intense, dangerous, or uncontrollable events are particularly likely to lead to such problems, especially if accompanied by illness, fatigue, or mood disturbances. ${ }^{5}$ Awareness under anaesthesia is an example of such an event.

Most accidents, and most medical accidents, do not produce post-traumatic stress disorder in its pure form. The long term consequences of the event, in terms of pain, disability, and effect on family relationships and ability to work will be much more important than the initial incident, and depression is a more usual response. Whether people actually become depressed and to what degree will depend on the severity of their injury; the support they have from family, friends, and health professionals; and various other factors. ${ }^{6} 7$

Studies of people involved in serious accidents (for example, road traffic accidents) suggest that $20-30 \%$ of patients experience long term psychological impairment. ${ }^{389}$ Accidental injury during treatment, although little researched, also seems to produce serious psychological symptoms. Vincent et al reported a study of patients injured during surgery and involved in or considering litigation. ${ }^{10}$ Damage to organs and nerves, perforations, and wound infections accounted for most of the injuries, the consequences of which were both sustained and severe. The overall effect on the patients, as judged by them, was considerable and included increased pain, disability, psychological trauma, and effects on their work and social lives. The patients frequently experienced disturbing memories, depression, and anxiety. Three quarters of them considered that the incident had had a severely detrimental effect on their life.

\section{When a patient dies}

Any bereavement entails multiple losses: the widow or widower loses companionship, a confidant, and a sexual relationship and may experience a loss of identity. Many bereaved people describe the loss in almost physical terms, as having part of them torn away. ${ }^{11}$ Bereavement may be particularly severe if the loss is untimely or unexpected ${ }^{12}$ or when the bereaved has had little forewarning about the loss. ${ }^{13} \mathrm{~A}$ bereavement that follows a sudden, accidental death may be exceptionally severe. Lehman et al, studying people four to seven years after they had lost a spouse or child in an accident, reported that many continued to 
ruminate about the accident and what could have been done to prevent it, and they seemed unable to accept, resolve, or find any meaning in the loss. ${ }^{1415}$

Relatives of patients whose death was sudden or unexpected may therefore find the loss particularly difficult to bear. If the loss was avoidable in the sense that poor treatment played a part in the death, the relatives may face an unusually traumatic and prolonged bereavement. They may ruminate endlessly on the death and find it hard to accept the loss.

After the incident: pathways to litigation Many patients and relatives involved in litigation consider that substandard care extended well beyond the original mishap. They are disturbed by absence of explanations, lack of honesty, reluctance to apologise, and being treated as neurotic. When explanations are given they are frequently thought to be unclear, insufficiently informative, and unsympathetic. ${ }^{1}$

The lack of explanation and other factors play a part in the decision to take legal action. There seem to be four main reasons for litigation (box). In order of importance: standards of care, both patients and relatives want to prevent similar future incidents; explanation, to know how the incident happened and why; compensation, for financial losses, pain and suffering, or to provide future care for an injured person; and, finally, accountability, considering that an individual or organisation should be held responsible. In some cases, of course, the need for compensation will be the overriding reason for litigation. If a child is seriously injured, for instance, the financial burden for a lifetime's care is colossal.

Main reasons for litigation
Standards of care
Explanation
Compensation
Accountability

These findings point, yet again, to the importance of communication in medicine, not just in the sense of having a pleasant manner but in the deeper sense of appreciating the patient's emotional state and understanding the needs of distressed or traumatised people. Communication assumes a special importance when things have gone wrong. Patients often blame doctors not so much for the original mistakes, as for a lack of openness or willingness to explain after the event. They feel that to err is human but that not to acknowledge errors is reprehensible. However, this is not to say that justified litigation for a serious injury can, or should, be deflected and smoothed over by a few friendly discussions.

Litigation may also stem, in part, from an initially poor relationship between doctor and patient. Two recent studies in the United States examining the malpractice history of Florida obstetricians found no relation between quality of care and claims history. However, patients of clinicians with a high rate of past claims against them were more likely to report feeling rushed, feeling ignored, receiving inadequate explanations or advice, and they spent less time during routine visits with their doctor. ${ }^{16} 17$

\section{Experiences of injured patients and their relatives}

Reports of studies help us to understand the main effects of injury to patients, but it is still difficult to grasp the full extent of the trauma that patients sometimes face. The following case histories attempt to flesh out the dry statistics and lists of symptoms. Risk managers, clinicians, and lawyers dealing with injured patients need to understand these experiences if they are to provide the necessary help and minimise the trauma to patients and their relatives. Providing this help will also, it must be said, reduce the chances of litigation and, when a case does ensue, reduce the damages awarded for pain and suffering.

The stories described below were all gathered in the course of interviews for reports. All the patients were involved in legal action, though not necessarily for large sums of money. In all cases substandard treatment was evident, although in some the most disturbing aspects of care were not, strictly speaking, negligent. None of the people involved had any prior history of psychological problems of any importance or of serious physical illness. The trauma they described was attributable to their treatment or that of their relative. The quotations are in the patient's or relative's own words taken from the interviews. Names and other identifying details have been changed to protect the anonymity of those involved. In these examples surgery and obstetrics are, unfairly, overrepresented, being among the specialties most at risk for litigation and, in financial terms, posing some of the worst problems. However, surgeons or obstetricians are not suggested to be any more or less likely to provide negligent care than other health professionals.

\section{Case 1 - Perforation of the colon: effect on the patient}

Mrs Long underwent a ventrosuspension - the fixation of a displaced uterus to the abdominal wall. After the operation she woke with a terrible pain in her lower abdomen, which became steadily worse over the next four days. She was very frightened and repeatedly told both doctors and nurses, but they did not take the pain seriously, dismissing it as "wind." On the fifth day the pain reached a crescendo. She felt a "ripping sensation" inside her abdomen, and the pain diminished. The surgeon (surgeon A) was called, again dismissed her complaints, and said that she could go home the following day. That evening the wound opened and the contents of her bowel began to seep through the dressings. Even then no one seemed concerned. When surgeon $A$ arrived to examine her "his face was a picture - as he finally realised something was wrong." Her bowel had been perforated. 
A temporary colostomy was carried out by surgeon B and, a few days later, a further operation was performed to close the wound before Mrs Long was discharged. The hospital promised that a nurse would attend twice daily at her home to help her with the colostomy. No one came.

Surgeon B, whom the patient liked and trusted, was away when the time came for the colostomy to be reversed a few months later. The next operation, by surgeon $C$, was "another fiasco." After a few days there was a discharge of faecal matter from the scar, the wound became infected and the pain was excruciating, especially after eating. Mrs Long persistently asked if she could be fed with a drip, but the nursing staff insisted she kept eating. For two weeks she was "crying with the pain, really panicking - I just couldn't take any more." She was finally transferred to another hospital, where she was immediately put on a drip and a liquid diet.

A final operation to repair the bowel was succesful but left her exhausted and depressed. She began to recover her strength only after a year of convalescence. Three years later she is still constantly tired, irritable, low in spirits, and "I don't enjoy anything any more." She no longer welcomes affection or comfort, in fact, she prefers to be alone. She feels that she is going downhill, becoming more gloomy and preoccupied. "I feel that I was strong at the time of the operation but now I'm just crumbling."

Mrs Long's scars are still painful at the time of her periods. Her stomach is "deformed" and she feels much less confident and attractive as a result. As her depression has deepened she has become less interested in sex and more self conscious about the scar. Three years later the trauma of her time in hospital is still very much alive. She still has nightmares about her time in hospital and is unable to talk about it without breaking into tears. She feels very angry and bitter that no one ever apologised to her or admitted that a mistake had been made.

Traumatic experiences, chronic pain, and physical weakness combined to produce a serious depression which lasted several years. It is remarkable how many patients injured during treatment report that at first they were not believed when they described their excessive pain. This particular series of errors and mishaps seems to have been partly due to the fact that three different surgeons were involved. The lack of communication between them and the lack of coordination in her care heightened Mrs Long's anxiety. She felt all along that no one person really knew what was wrong with her or had full responsibility for her treatment.

Case 2 - Asphyxia during labour: effect on the mother

Mrs Farr's daughter Polly, now six, has severe cerebral palsy after an injury at birth. Polly's intellectual abilities do not seem to be seriously impaired, but she is severely physically handicapped.

After the birth Mrs Farr was told that Polly had sustained an injury to her brain, but at first she could not really take in this information or comprehend the full implications - "we were just in total shock." Polly had been taken to intensive care, and when she came back to the ward it took a long time to convince Mrs Farr that she was actually her child. After she returned home with Polly, Mrs Farr hid herself away and pretended everything was all right. It was some weeks before she telephoned a friend and told her "Polly's brain damaged." She said that this was one of the worst things that she had to do.

For the first eight months of Polly's life $\mathrm{Mr}$ and Mrs Farr had very little professional help. They had the usual paediatric check ups, seeing registrars who "didn't want to know about Polly," and an "absolutely hopeless" health visitor. They desperately wanted more information and to talk to other people who had children with similar disabilities. They had no idea what to expect or what kind of future Polly might have. After eight months Mrs Farr joined a small support group of mothers and children with similar problems run by a physiotherapist who "became my lifeline." Otherwise, she was extremely isolated, apart from nightly telephone calls to her mother.

In the first years of Polly's life Mrs Farr cried constantly and blamed herself for everything. She felt that "they'd taken away the baby I should have had and I'd been given Polly." It seemed to her that her real baby had died and she was grieving for the child she had never had. She felt that Polly would be better off dead and on many occasions threatened to kill both herself and Polly. Mr Farr would leave the house each morning knowing that they both might be dead when he returned. The physical demands of caring for Polly coupled with the anguish and threats of suicide all but destroyed the marriage. There was no improvement in Mrs Farr's mood for three years until she became pregnant again and Polly started school. Until then Polly needed 24 hours attention and she felt "totally trapped."

Mrs Farr copes remarkably well with the enormous physical and emotional demands of caring for Polly. However, she is constantly on edge and finds it almost impossible to relax. "Always in the back of my mind there's something I have to do. I dream about this I'm always in a panic, always disorganised and out of control." She does everything possible to make Polly's life as good as it can be, but "even now I don't really feel bonded to Polly I just care for her."

After five years the hospital finally admitted liability. Although no one had ever suggested Mrs Farr was to blame, she felt intensely ashamed and guilty before that. Finding out that Polly was injured during the labour has eased some of these feelings and, for the first time, offered some prospect of compensation and help for Polly.

Most of Mrs Farr's problems face all mothers of seriously handicapped children. The grief at the loss of the child that was expected combined with the grinding responsibility of 24 hour care can break the strongest person. It is remarkable then that almost none of the various professionals involved with Polly thought to ask how Mrs Farr was; a few brief questions would have 
quickly elicited the fact that she was actively suicidal.

If more resources were available, awards would not need to be made for a lifetime's care in the private sector. Services are not adequate, which is one of the reasons for the massive awards made when negligence is shown. However, an admission of liability need not have taken five years; even then, no help was offered. The solicitors then entered another battle for interim payments to provide some basic facilities for Polly. The hospital's duty of care to Mrs Farr seems to have ended, as far as it was concerned, once litigation began. An early offer of compensation, probably in the form of a structured settlement, would have been comparatively cheap for the trust concerned to institute. Polly's needs could then have been reviewed and payments adjusted accordingly, to the benefit of everyone concerned. ${ }^{18}$

\section{Case 3 - Neonatal death: effect on the father}

Mr Carter's son, Jamie, sustained injuries at birth, causing irreparable injury to his spinal cord. He died when he was two months old without regaining consciousness.

Late in the labour Mr Carter saw that the midwife had become "rather flustered - I should have realised then that something was wrong." When Jamie was delivered "the cord was round his neck. He wasn't in a good state - even I could see that. If he had died then it would have been much easier for us." Three days after the birth a paediatrician confirmed that their son was, as they suspected, severely handicapped. He had fits and was partially sighted. He never cried or made any sounds because his vocal cords had been damaged. Despite his injuries he continued to grow and put on weight. Two weeks after the birth Jamie's parents were told that he would not live. They then spent a terrible two months, mostly at the hospital, waiting for him to die.

$\mathrm{Mr}$ and Mrs Carter had several meetings with hospital staff, but Mr Carter never felt he had received a full explanation. He remembers being told that "it was just one of those things - that really sent me sky rocketing. No one said it was a mistake, that's what wound me up. Till this day I've got many questions. No one acted quickly enough. No doctor came at all until the paediatrician."

Mr Carter's reaction to Jamie's death was intense, violent, and prolonged. For a year he had disturbing memories and horrific dreams. He became quiet, withdrawn, and remote, even from his wife, feeling "empty and hopeless." He was tormented by disturbing images and memories of Jamie; of the birth; of his slow death; and, particularly, of his small, shrunken skull toward the end. Images of Jamie's birth still "popped into my head at the most unexpected times. Very vivid, just like looking in on it. It just graps you round the throat..." He had a persistent stress related stomach disorder. His sleep was interrupted by violent nightmares of a kind he had never previously experienced. "There was all this blood and gore, fantasy-like stuff." During the day violent images, sometimes of killing people, would come into his head, which absolutely horrified him.
Before Jamie's death Mr Carter had always been a relaxed and easygoing person. Now he was easily irritated, and there were many arguments between him and his wife. At work his irritability would often turn to anger, leading to confrontations and sometimes to fights. "I was really angry all the time, so aggressive - I wanted to hurt people, and I'm not like that at all. I felt I had to blame someone all the time for everything."

About a year later Mrs Carter became pregnant again. Mr Carter was very anxious during the pregnancy but his symptoms began to subside after their daughter was born. Two years later he still breaks down and cries occasionally, and is generally a sadder and quieter person. When he passes the cemetery where his son is buried he still becomes angry, but now the feelings subside.

Many of the symptoms and experiences reported by $\mathrm{Mr}$ Carter are common in any bereavement. Depression, distressing memories, feelings of anger, and dreams of the person who has died are not unusual. However the intensity, character, and duration of $\mathrm{Mr}$ Carter's reaction indicate that this was far from an ordinary bereavement. Anger of that intensity and violent daydreams are not usual and show that he had post-traumatic stress disorder. The staff of the paediatric unit clearly tried to help the parents, although $\mathrm{Mr}$ Carter still felt that the full story was being hidden from him. Later reports suggested that he was right. If Jamie's death had been unavoidable $\mathrm{Mr}$ Carter would probably still have found an explanation very difficult to accept, given the severity of his emotional reaction. The staff did not seem to realise what he was suffering. They did not ask and he did not tell them.

\section{What to do?}

Every injured patient has their own particular problems and needs. Some require a great deal of additional help, others prefer to rely on their family and friends. Some will primarily require remedial medical treatment, while in others the psychological effects will be to the fore. Nevertheless, several basic considerations will help in dealing with anyone who has been injured or seriously distressed by their treatment, whether or not negligence or litigation is involved. These suggestions (box) are derived from patients, their relatives, researchers and from other writers on this topic. ${ }^{19-21}$

\section{What to do for people injured or} distressed by treatment

(1) Believe people who say their treatment has harmed them

(2) Give an early explanation

(3) Continuity of care or referral?

(4) Maintain the therapeutic relationship

(5) Ask specific questions about emotional trauma

(6) Consider counselling or psychotherapy

(7) Inform patients of changes

(8) Offer compensation

(9) Consider mediation

(10) Consider wider implications 
BELIEVE PEOPLE WHO SAY TREATMENT HAS HARMED THEM

Patients who consider that they have been injured during their treatment should in the first instance be believed. In many cases they may have had unrealistic expectations of their treatment or have not fully understood the risks entailed; in a few they may be malingering or hypochondriacal. However, if $4 \%$ of admissions result in some kind of injury to the patient $^{22}$ then a report of such an injury should at least be seen as credible. It should certainly not be automatically seen as evidence of personality problems, or of being "difficult," or even as necessarily being threatening to the staff involved. Being believed is extremely important for accident victims and, conversely, not being believed is always frustrating and can be intensely disturbing.

EARLY EXPLANATION

Many studies showed that patients are generally dissatisfied with the information that they are given in the ordinary course of treatment. ${ }^{23}$ The lack of a clear and convincing explanation is especially distressing when something has gone wrong. When patients think that information is being concealed from them or that they are being dismissed as troublemakers it becomes much more difficult for them to cope with the injury. A poor explanation fuels their anger, may affect the course of a bereavement, and may lead patients to distrust the staff caring for them. They may then avoid having further treatment, which in most cases they very much need.

When something has gone wrong a senior doctor needs to give a thorough and clear account of what exactly happened. At the first interview junior staff involved with the patient may also be present. The patient and their relatives need to have time to reflect on what was said and to be able to return and ask further questions. Several meetings may be needed over the course of weeks or months. Similar considerations of course apply when doctors are breaking bad news of any kind. ${ }^{24}$

\section{CONTINUITY OF CARE OR REFERRAL?}

A patient harmed by treatment poses acute and painful dilemmas for the staff involved. It is natural to avoid that pain by avoiding the patient, yet the staff's response is crucial to the patient's recovery.

The awful sinking feeling that comes with the realisation of a clinical error, particularly one whose consequences for the patient may be serious, must be familiar to all experienced practitioners. . . Sharing with the patient the realisation of that error, admitting that it has occurred and facing squarely the responsibility for it requires courage. Nevertheless such an approach is appreciated by the patient. ...21

Clements discusses this issue with sensitivity and clarity. In essence, he suggests that when the explanation is innocent and accepted by the patient, treatment can simply continue. When nothing has in fact gone wrong, but the patient believes it has, a referral to another doctor may be the only course. A much more difficult situation arises when care has been substandard. Clearly, the patient must be offered a referral elsewhere if that is what they wish but:

Our experience is that, even under such circumstances, the patient will often choose to continue under the care of the same doctor. Paradoxically her faith in that doctor may well have been enhanced. ${ }^{21}$

\section{MAINTAINING THE THERAPEUTIC}

RELATIONSHIP

Injured patients may receive support, comfort, and practical help from many sources. It may come from their spouse, family, friends, colleagues, doctors, or community organisations. An especially important source of support will be the doctors and other health professionals who are involved in their treatment.

Both patients and doctors may change their attitudes to each other after medical accidents. Patients commonly trust less both their doctor's competence and them personally. The reaction of staff varies considerably. Some become more attentive and caring, but many injured patients find that staff attitudes change for the worse. Typical comments are that the staff were more withdrawn and distant and gave patients less information. ${ }^{10}$

Patients who have been injured during treatment may need more time and support than other patients. An honest explanation and a promise to continue treatment may enhance the patient's trust and strengthen the relationship. After an initial mistake it is extremely reassuring for a patient to be overseen by a single senior doctor who undertakes to monitor all aspects of treatment, even if it involves several different specialties.

Even the best and most sympathetic care can lead to unexpected difficulties. After one avoidable stillbirth a full explanation was offered and the parents were given extensive support. In a final interview the parents expressed their gratitude to the staff. However, the mother was left with a sense of emptiness and frustration:

I sometimes think it would have been better if I had had somebody to hate. As it was everybody said how sorry they were and I couldn't even get angry even though my baby had died. ${ }^{21}$

Clements comments: "The doctors and midwives in sharing their grief with the parents had effectively neutralised their justifiable anger at the unnecessary loss. Perhaps we went too far and in expressing our own grief put an unreasonable burden on the parents, allowing them to feel sympathy for us. It is not easy to get it right. The care of the injured or bereaved patient . . . should at all times remain balanced and not take advantage of the injured patient's vulnerability to attract sympathy. It is after all their loss, not ours. ${ }^{21}$

ASK SPECIFIC QUESTIONS ABOUT EMOTIONAL TRAUMA

A common theme of interviews with injured patients is that none of the professionals 
involved in their care appreciated the depth of their distress. In many cases outright psychiatric disorders were missed. Risk managers, clinicians, and others can ask basic questions without fear of "making things worse." The case histories illustrate some of the most common reactions and experiences of people with depression and post-traumatic stress disorder. Other crucial areas of inquiry are feelings of anger, humiliation, betrayal, and loss of trust - all of which are commonly experienced by injured patients.

CONSIDER COUNSELLING OR PSYCHOTHERAPY A proportion of patients are probably sufficiently anxious or depressed to warrant formal psychological or psychiatric treatment. Although it is important that a consultant is involved in giving explanations and monitoring remedial treatment, expecting the staff of, say, a surgical unit to shoulder the burden of formal counselling is unrealistic. They have neither the time nor the necessary training to deal with the more serious reactions.

A referral to a psychologist or psychiatrist may be clearly indicated but must be carefully handled. Injured patients are understandably very wary of their problems being seen as "psychological" or "all in the mind." This may be especially true of referrals to a psychiatrist who may (however unfairly) be seen as dealing with mental illness rather than simply offering support and treatment. In a large trust a specialist counsellor may be warranted. This would benefit both injured and traumatised patients and the staff who care for them. Whoever the therapist, it is fundamental that he or she accepts the reality of the patient's injury and does not attempt to explain the patient's reaction away on the basis of past psychological problems. Some patients report that their therapist found it extremely difficult to talk straightforwardly about injuries caused by treatment.

In some circumstances a therapist or counsellor not connected with the trust or practice concerned may be better. Clearly this is necessary if the patient no longer trusts the staff who cared for him or her, but it may help even when the staff are continuing to care for the patient. As the example of the stillbirth above shows, a patient may be unable to disclose the anger they feel when the staff are also distressed. One of the great values of an outside therapist is that the patient can safely rage, break down, and admit to violence and irrational feelings in safety and without fear provided the therapist has the necessary qualities of equanimity and acceptance.

INFORM PATIENTS OF CHANGES

Patients' and relatives' wish to prevent future incidents can be seen both as a genuine desire to safeguard others and as an attempt to find some way of coping with their own pain or loss. The pain may be ameliorated if they feel that because changes were made at least some good came of their experiences. Relatives of patients who have died may express their motives for litigation in terms of an obligation to the dead person to make sure that a similar accident never happens again, so that some good comes of their death.

The implication is that patients should be informed if changes have been made as a result of the error and if retraining of staff or disciplinary action is to be instituted. Although some patients may regret that the changes were made too late for them, most will appreciate the fact that their experience was understood and acted on. However, letters from administrators not involved in clinical work, stating simply that "the necessary steps have been taken to prevent a recurrence" clearly do not convince and often fuel people's anger. ${ }^{25}$

\section{OFFER COMPENSATION}

Injured patients need help immediately. They need medical treatment, counselling, explanations, but they often need money as well. They may need to support their family while they are recovering, to pay for specialist treatment, facilities to cope with disability, and so on.

For example, Mrs Farr's life would have been immeasurably improved with an early, properly structured settlement providing her with facilities to care for her daughter and with respite care. In less serious cases an early award of a few thousand pounds to provide private treatment, alterations to the home, or additional nursing may make an enormous difference to the patient both practically and in their attitude to the hospital. Clearly, ethical reasons exist for offering compensation when a patient has been injured: it should be seen as part of continuing care. There are also sound financial reasons: help someone at an early stage and the trust or general practitioner will face lower legal bills and much smaller claims for pain and suffering.

\section{CONSIDER MEDIATION}

The legal process may, in various ways, exacerbate the problems facing both patients and staff. It is in everyone's interests, except a certain type of lawyer, that disputes should be settled without recourse to litigation or, at the very least, early in the legal process. Mediation and alternative dispute resolution are not panaceas, and it is essential that the mediator is skilful and appropriately trained. Nevertheless, this option should always be considered if the matter is sufficiently serious and especially if litigation seems likely (for a full discussion see Brown and Simanowitz (p 151) ${ }^{26}$ ).

\section{CONSIDER THE WIDER IMPLICATIONS}

The stories described in this chapter, though serious, are comparatively rare. They might seem to be isolated instances, which do not reflect the overall quality of care. A theme throughout this special issue on risk management is that the study of individual adverse events can often disclose wider problems. ${ }^{27}$ Similarly, the way staff react to serious incidents may disclose a more general pattern of good or bad communication and a greater or lesser awareness of patients' experiences. If patients injured by treatment consistently 
claim that they had to fight to get a proper explanation other patients in the unit or practice may be struggling to get the information they need.

I thank the people who gave permission for their stories to be used, and Roger Clements, Fiona Moss, Angela Phillips, and Arnold Simanowitz for their comments.

1 Vincent C, Young M, Phillips A. Why do people sue doctors? A study of patients and relatives taking legal action. Lancet 1994;343:1609-13.

2 Mills DH. Clinical risk management: experiences from the United States. Quality in Health Care 1995;4:90-6.

3 Landsman IS, Baum CG, Arnkoff DB, et al. The psychological consequences of traumatic injury. 7 Behav Med 1990;13:561-81

4 Davidson JRT, Foa EB. Diagnostic issues in post-traumatic stress disorder: considerations for DSM-IV. F Abnormal Psychol 1991;100:346-55.

5 Rachman S. Emotional processing. Behav Res Ther 1980;18:51-60.

6 Brown GW, Harris T. Social origins of depression. London: Tavistock Publications, 1978.

7 Vincent CA, Robertson I. Recovering from a medical accident: the consequences for patients and their families. In: Vincent CA, Ennis M, Audley RJ, eds Medical accidents. Oxford: Oxford University Press, 1993:150-66.

8 Malt U. The long-term psychiatric consequences of accidental injury. $B r \mathcal{F}$ Psychiatry 1988;153:810-8.

9 Mayou R. Psychiatric consequences of road traffic accidents. BMF 1993;307:47-51.

10 Vincent CA, Pincus T, Scurr JH. Patients' experience of surgical accidents. Quality in Health Care 1993;2:77-82.

1 Parkes CM, ed. Bereavement: studies of grief in adult life. London: Penguin, 1988.

12 Vachon MLS, Rogers J, Lyall A, Lancee WJ, Sheldon AR, Freeman SJJ. Predictors and correlates of adaption to conjugal bereavement. Am $f$ Psychiatry 1982;139: 998-1002.
13 Lundin T. Morbidity following sudden and unexpected bereavement. $B r \mathcal{F}$ Psychiatry 1984;144:84-8.

14 Lehman DR, Wortman CB, Williams AF. Long-term effects of losing a spouse or child in a motor vehicle crash. F Pers Soc Psychol 1987;52:218-31.

15 Lehman DR, Lang EL, Wortman CB, Sorensen SB. Longterm effects of sudden bereavement: marital and parentchild relationships and children's reactions. Fournal of Family Psychology 1989;2:344-67.

16 Entman SS, Glass CA, Hickson GB, et al. The relationship between malpractice claims history and subsequen between malpractice claims history and
obstetric care. $7 A M A$ 1994;272:1588-91.

17 Hickson GB, Clayton EW, Entman SS, et al. Obstetricians' prior malpractice experience and patients' satisfaction with care. FAMA 1994;272:1583-7.

8 Clements $\mathrm{R}$, Huntingford $\mathrm{P}$, eds. Safe practice in obstetrics and gynaecology. London: Churchill Livingstone, 1994.

19 Simanowitz A. Standards, attitudes and accountability in the medical profession. Lancet 1985;ii:546-7.

20 Bennet G. After an accident around childbirth. In: Clements R, Huntingford P, eds. Safe practice in obstetrics and gynaecology. London: Churchill Livingstone, 1994: and gynaect

21 Clements $\mathrm{R}$. The continuing care of the injured patient. In Clements R, Huntingford P, eds. Safe practice in obstetrics and gynaecology. London: Churchill Livingstone, 1994

22 Hiatt $\mathrm{HH}$, Barnes BA, Brennan TAEA. A study of medical injury and malpractice. New Engl $\mathcal{f}$ Med 1989 321:480-4

23 Ley P. Improving patients' understanding, recall, satisfaction and compliance. In: Broome AK, ed. Health psychology: processes and applications. London: Chapman and Hall, 1989:74-102.

24 Finlay I, Dallimore D. Your child is dead. BMF 1991; 302:1524-5.

25 Bark P, Vincent CA, Jones A, Savory J. Clinical complaints: a means of improving quality of care. Quality in Health Care 1994:3:123-32.

26 Brown H, Simanowitz A. Alternative dispute resolution and mediation. Quality in Health Care 1995;4:151-8.

27 Reason J. Understanding adverse events: human factors Quality in Health Care 1995;4:80-9. 